\title{
Padronização do Teste Desiderativo no Contexto da Análise Transacional: Resultados Preliminares
}

\author{
Guenia Bunchaft ${ }^{1}$ \\ Universidade Federal do Rio de Janeiro \\ Vanda Leite Pinto Vasconcellos \\ União Nacional dos Analistas Transacionais
}

\begin{abstract}
RESUMO - Este artigo aborda um teste projetivo - o Teste Desiderativo, e as autoras trabalharam com vistas à sua padronização, usando a Análise Transacional, como linha teórico-referencial. Com este objetivo, realizaram uma pesquisa com uma amostra de 552 alunos universitários. Uma forma coletiva do teste foi aplicada aos sujeitos. Os principais achados foram: a ordem das escolhas e rejeições não foi a mesma encontrada por Ocampo, uma especialista do Teste Desiderativo. Sugere-se um aumento do número de perguntas, de modo a discriminar entre ser inanimado, força natural/fenômeno da natureza e abstração; as escolhas mais freqüentes foram: Pássaro, Árvore, Estrela e Flor; as rejeições mais freqüentes foram: Pedra, Capim/Grama e Rato; tais respostas foram consideradas vulgares; as razões mais freqüentemente mencionadas para as escolhas foram: Liberdade; Impacto Estético; Utilidade/Reparação; Despertar Admiração/Fascinar; Movimento e Poder/Controle; as razões mais freqüentemente mencionadas para as rejeições foram: Agressividade/Destruição; Dano; Sensações Desagradáveis; Sentimentos Desagradáveis; Submissão e Sujeira. As autoras fizeram uma primeira tentativa de interpretação do teste, em termos de Análise Transacional.
\end{abstract}

Palavras-chave: Teste Desiderativo; padronização; Análise Transacional; teste projetivo.

\section{Standardization of the Pigem's Test in the Context of Transactional Analysis: First Results}

\begin{abstract}
This article is an approach to a projective test, the Pigem's test, and the authors have worked with a view to its standardization, using the Transacional Analysis as theoretical guideline. With this aim, they conducted a research, having 552-university students as a sample. A colective form of the test was applied to the subjects. The main findings were: The order of the choices and rejections was not the same found by Ocampo, a scholar specialized in the Pigem's Test. It is suggested an enlargement of the number of questions, to discriminate between lifeless being, natural force/natural phenomenon and abstraction. The more frequent choices were: Bird; Tree; Star and Flower; the more frequent rejections were: Stone; Grass and Mouse (the rodent); these answers were considered vulgar ones; The reasons more often mentioned for the choices were: Freedom; Esthetic Impact; Utility/Reparation; To be Admired/To Fascinate and Power/Control; the reasons more often mentioned for the rejections were: Aggresiveness; Destruction; Damage; Unpleasant Sensations; Unpleasant Feelings; Submission and Filthiness. The authors produced a first interpretation of the test, in the terms of Transactional Analysis.
\end{abstract}

Key words: Pigem's test; standardization; Transactional Analysis; projective test.

Este trabalho teve como objetivo realizar uma padronização preliminar do Teste Projetivo Desiderativo, adaptado pelas autoras como um instrumento de aplicação coletiva, tendo como referencial teórico a Análise Transacional. Na medida em que o leitor, mesmo que seja psicólogo, não tenha formação específica nas áreas de Medidas e Testes em Psicologia, nem na teoria da Análise Transacional, consideramos importante clarificar algumas noções.

O que é padronizar um teste? É estabelecer critérios para a interpretação dos resultados do indivíduo em um grupo representativo (ou normativo, pois mostra o que "normalmente" se espera encontrar). Este grupo deve ser um grupo tal que as características relevantes para o aspecto que está sendo avaliado sejam semelhantes às do indivíduo que está sendo examinado.

1 Endereço: Rua Barão de Itambi n 7 apt $^{\circ} 111$, Botafogo - RJ. CEP: 22231-000.E-mail: guenia.bunchaft@infolink.com.br
O resultado do indivíduo em um teste, seja ele qual for, não tem um significado absoluto, só tem sentido quando comparado aos resultados do grupo representativo. Por exemplo: João faz uma prova na escola e obtém nota cinco. O que essa nota significa, além de mostrar que ele acertou a metade da prova? Se a turma da escola em que ele estuda apresentar como média na prova a nota oito, ele teve um desempenho fraco; por outro lado, se a média da turma foi dois, ele mostra um desempenho superior aos de seus colegas.

Então, a padronização nos indica o desempenho grupal em um determinado teste, estabelecendo-se critérios objetivos para a avaliação do indivíduo. Quando se trata de testes projetivos, cuja interpretação é mais subjetiva que nos testes objetivos, mostra-se ainda mais relevante estabelecer critérios referenciais para a correção dos protocolos de testes, o que minimiza o "achismo". Por exemplo, a percepção da resposta morcego na prancha $\mathrm{V}$ do Psicodiagnóstico de Rorschach pode ser considerada por um leigo no assunto como uma resposta de conteúdo negativo. Estudos de pa- 
dronização, no entanto, mostram que essa resposta é vista pela maioria das pessoas, sendo considerada vulgar; indica, assim, o critério de realidade do indivíduo: em Análise Transacional seria um índice do Estado do Eu Adulto.

Os testes projetivos (p. ex. Psicodiagnóstico de Rorschach, Teste Desiderativo etc.) são constituídos por material ambíguo, pouco estruturado, em que o indivíduo está livre para responder; isto facilita a projeção de aspectos mais profundos da personalidade. Se perguntarmos ao indivíduo o que ele gostaria de ser se não fosse uma pessoa (primeira pergunta do Desiderativo), qualquer resposta é aceitável e vai evidenciar as características estruturais e dinâmicas de sua personalidade.

O Teste Desiderativo foi apresentado em sua forma original em 1946, pelos psiquiatras J.M. Pigem e J. Córdoba, em seu artigo La expressión desiderativa como manifestación de la personalidad. Consistia em duas questões: o que você gostaria de ser se tivesse de voltar ao mundo não sendo uma pessoa? Por que você fez essa escolha? O que foi escolhido corresponde ao símbolo desiderativo e o porquê da escolha à expressão desiderativa. Van Kravelen (Apud Bernstein, $1948 / 1980$, p. 268) adaptou as instruções para crianças, pedindo uma escolha com a sua justificativa e uma rejeição (o que não gostaria de ser) com a sua justificativa. Finalmente, J. Bernstein (1948/1980, p. 263-264) reelaborou e ampliou o instrumento, solicitando três escolhas e três rejeições com suas respectivas explicações. As instruções são fornecidas de modo que resultam, tanto das escolhas como das rejeições, um animal, um vegetal e um ser inanimado. Após a primeira escolha do sujeito, ante a questão: "o que você gostaria de ser se não fosse uma pessoa? Por que?" o examinador elimina a categoria escolhida na primeira resposta e formula nova questão, obtendo assim uma segunda resposta. $\mathrm{O}$ mesmo se aplica à terceira escolha. $\mathrm{O}$ procedimento para as rejeições é o mesmo; na primeira rejeição o sujeito tem total liberdade de opção e nas segunda e terceira vão sendo eliminadas as categorias escolhidas. Por exemplo, se à primeira pergunta o sujeito responde que gostaria de ser um cavalo, na segunda o examinador pergunta: "Se você não pudesse ser uma pessoa nem um animal, o que você gostaria de ser?" Como a categoria animal (no exemplo, cavalo) já foi emitida, ela é eliminada.

Com base em nossa experiência na aplicação do teste, a categoria ser inanimado passou a englobar conteúdos abstratos, resultando na categoria abstração (como exemplo de ser inanimado temos: mesa, cadeira, pedra e de abstração temos amor, paz etc).

Quando de sua elaboração, a interpretação do Teste Desiderativo não remetia a uma infraestrutura teórica organizada. Após a ampliação das instruções por J. Bernstein (1948/1980), passou a ser muito utilizado nos países de língua espanhola. Sua interpretação então começou a ser feita com base nas concepções de Melanie Klein, especialista em psicanálise infantil.

M. Klein (1955/1980) procurou no primeiro ano de vida da criança a explicação para todos os processos que se desenvolvem no ser humano. Formulou então teorias relativas à ansiedade, defesas e relações objetais ocorrentes nesse período.
Segundo essa autora (citada por Segal, 1964/1975, p. 3649), as crianças nos primeiros três ou quatro meses de vida sentem o que ela denominou de ansiedade persecutória. Nessa etapa, denominada posição esquizo-paranóide, alternam-se os mecanismos de introjeção, projeção, e divisão (splitting); é então formado o Ego. A principal ansiedade é de que o Ego seja destruído pelo objeto ou objetos maus.

Este Ego se divide (splits) e projeta. no seio o instinto de morte, dividindo-o em vários pedaços (splitting). A libido também é projetada para o objeto que satisfaz o esforço do Ego pela preservação da vida. O seio, nesse período, é dividido (split) em duas partes: o seio ideal e o seio persecutório. A divisão está ligada à idealização crescente do objeto ideal, a fim de mantê-lo bem distante do objeto perseguidor.

Outro mecanismo de defesa desenvolvido nessa fase é a identificação projetiva, em que partes do eu e objetos internos são expelidos e projetados no objeto externo, que controla e se identifica com as partes projetadas.

A segunda etapa da vida da criança, que vai dos três ou quatro meses aos seis meses é denominada posição depressiva. Nela, o bebê se "reconhece como um objeto total e se relaciona com ele" (Segal, 1964/1975, p. 81). Assim como a mãe se torna um objeto total, o ego do bebê é cada vez menos dividido (split) em seus componentes bons e maus. Além disso, a criança se relaciona com outros objetos como o pai, irmãos e outros. A ansiedade depressiva leva a criança a estabelecer uma forte identificação com a mãe, que é internalizada.

Para contrabalançar a ansiedade depressiva, o Ego utiliza o que M. Klein denomina "defesas maníacas". A ansiedade é desencadeada, então, pela ambivalência; o bebê fica ansioso de que seus próprios impulsos destrutivos destruam o objeto que ele ama e do qual depende completamente. Segundo H. Segal (1964/1975). “A organização de defesas maníacas na posição depressiva inclui mecanismos que já estavam em evidência na posição esquizo- paranóide: divisão (splitting), idealização, identificação projetiva, negação etc" (p.95).

$\mathrm{O}$ que distingue o uso dessas defesas em uma ou outra posição é que agora elas são mais bem organizadas e direcionadas contra a experiência de ansiedade depressiva e culpa.

Ocampo e Garcia Arzena (1976), discípulas de Bernstein na aplicação e interpretação do Teste Desiderativo, baseiam essa interpretação nos conceitos teóricos de M. Klein. Para estas autoras, o teste em questão permite que se estude a força do Ego, os mecanismos de defesa e os índices diagnósticos e prognósticos, a partir de uma melhor exploração e categorização do material obtido face às instruções desse teste.

Além dessas autoras, para Schust \& Piccolo (1976) o teste evidencia o diagnóstico das fantasias inconscientes defensivas predominantes em cada sujeito: esquizóides ou maníacas.

Uma das críticas relevantes feitas à utilização dos testes projetivos refere-se aos dados precários relativos ao seu processo de validação, aí incluindo a padronização dos resultados. Seguindo a proposta de Klopfer e seus colaboradores 
(1946/1974), consideramos que a pesquisa concernente aos testes projetivos é um processo de retroalimentação entre teoria e prática, que provoca mudanças entre elas. A inexistência, tanto quanto é do nosso conhecimento, de estudos de padronização do Teste Desiderativo, evidencia a importância de realizá-los. Optamos por utilizar a Análise Transacional como referencial teórico alternativo à Psicanálise Kleiniana pois consideramos que a AT poderá fornecer uma linha de interpretação completa da estrutura e dinâmica da personalidade. Dentro desse enfoque, pretendemos obter subsídios para a avaliação dos Estados do Eu, Compulsores, Mandatos, Ameaças Argumentais, Fantasias e Defesas em torno da morte e da perda de identidade.

Consideramos oportuna a utilização da Análise Transacional como substrato teórico para a interpretação dos testes projetivos, dada a sua percepção positiva da natureza humana, a ênfase nos determinantes conscientes do comportamento, a posição intermediária no eixo idiográfico-nomotético e a aceitação dos princípios holísticos. ${ }^{2}$

A análise estrutural em Análise Transacional aborda a personalidade como sendo constituída por três Estados do $E u$, que se expressam por comportamentos visíveis.

Estado do Eu é um sistema de pensamentos e sentimentos que se expressam por meio de manifestações comportamentais. Berne (1972) chamou de Estado do Eu Pai aquele sistema que é formado por normas internalizadas a partir das influências parentais e culturais, correspondendo aos conceitos "ensinados". O Estado do Eu Adulto é o "computador" da personalidade, corresponde àquilo que é pensado. O Estado do Eu Criança compreende as emoções, sensações e processos biológicos, ou seja, aquilo que é sentido pelo indivíduo.

Uma análise de segunda ordem dos Estados do Eu mostra que o Estado do Eu Pai apresenta dois aspectos: (a) Pai Crítico (PC), evidenciado por comportamentos firmes e justos (PC "ok" $)$ ou por agressividade e autoritarismo (PC não ok); Pai nutritivo (PN), que se destaca por condutas afetivas e protetoras (PN “ok") ou superprotetoras (PN não ok).

O Estado do Eu Adulto pode se apresentar ético, responsável, informado (Adulto "ok") ou desonesto, desinformado, "robotizado" (Adulto "não ok").

Já o Estado do Eu Criança se subdivide em (a) Criança Livre (CL) que se manifesta de forma criativa, espontânea e intuitiva (CL "ok"); (b) Criança Adaptada (CA) que evidencia dois aspectos - Criança Submissa (CS) e Criança Rebelde (CR).

A Criança Submissa caracteriza-se pela resposta automática a disciplina e rotinas convenientes (CS “ok") ou pela desvalorização e submissão do indivíduo (CS “não ok”).

2 Essa abordagem da Análise Transacional como alternativa à psicanálise na interpretação dos testes projetivos foi feita no artigo "Os testes projetivos em uma perspectiva não psicanalítica" (Bunchaft \& Vasconcellos, 1998).

3 O conceito de "okeidade", termo americano de difícil tradução, se refere à utilização dos Estados do Eu em um sistema positivo (ok) de conduta e de forma adequada aos estímulos recebidos. O sistema "não ok" é conceituado de forma contrária ao sistema "ok".
Finalmente, a Criança Rebelde é considerada “ok" quando o indivíduo manifesta indignação por um motivo justo e "não ok" quando o indivíduo se mostra rebelde e agressivo.

O conceito que cada indivíduo tem de si mesmo e dos demais configura a Posição Existencial (P.E.). Dependendo de como o indivíduo percebe a si mesmo e aos outros, ele assume uma das seguintes posições:

Eu estou "ok" / você não está "ok" (+/-), em que o indivíduo coloca nos outros todos os aspectos negativos.

Eu não estou "ok" / você está "ok" (-/+), em que o indivíduo se percebe de modo negativo e aos outros de modo positivo, o que resulta em dificuldade de relacionamento.

Eu não estou "ok" / você não está "ok" (-/-), em que o indivíduo só percebe aspectos negativos em si mesmo e nos demais.

A psicoterapia se propõe, dentre outras metas, a levar o indivíduo a adotar a Posição Existencial Realista $( \pm / \pm)$, percebendo a si mesmo e aos demais de forma positiva mas não idealizada.

O Script ou Argumento é um "plano preconsciente de vida, decidido antes dos 14 anos, sob a influência parental, que dirige a conduta do indivíduo nos aspectos mais importantes de sua vida" (Berne, 1972, p. 41). O Script é desenvolvido a partir das mensagens parentais internalizadas pela criança. Essas mensagens são denominadas Mandatos - o que o indivíduo deve fazer para cumprir o Script. São exemplos de Mandatos: Não sintas; Não desfrutes; Não penses; Não sintas o que sentes etc.

Para contrabalançar os Mandatos que os progenitores "gravam" involuntariamente na mente dos filhos, os pais emitem mensagens contra-argumentais verbais, socialmente edificantes, denominadas Compulsores. Estas mensagens foram classificadas por Kahler (apud Kertesz \& Induini, 1977) em cinco categorias : Seja Perfeito; Seja Forte; Agrade Sempre; Seja Apressado; e Seja Esforçado.

A saída do Script com seus Mandatos e Compulsores, acarretaria uma Maldição ou Ameaça Argumental - aquilo que a Criança do indivíduo acredita que vai acontecer com ele se o mandato for quebrado: Ficar Louco; Morrer; ou Ser Abandonado.

\section{Método}

\section{Amostra}

A amostra constou de 552 alunos dos primeiro e segundo períodos de crédito da Universidade Santa Úrsula dos seguintes cursos: Arquitetura, Biblioteconomia, Ciências Contábeis, Economia, Engenharia Mecânica, Engenharia Elétrica, Letras, Nutrição, Pedagogia e História, solicitados a colaborar em uma pesquisa realizada pelo curso de Psicologia.

\section{Procedimentos para a aplicação do Teste Desiderativo}

As autoras elaboraram uma forma coletiva para aplicação do Teste Desiderativo, seguindo as linhas básicas pro- 
postas por Bernstein (1948/1980), porém direcionando os sujeitos para que fornecessem como respostas positivas e negativas um animal, um vegetal e um ser inanimado/abstração. Após a primeira escolha (primeira rejeição) o sujeito era solicitado a identificar a categoria da resposta escolhida/ rejeitada de modo a eliminar esta categoria na(s) próxima escolha/rejeição, ou seja na segunda e terceira opções. Como a primeira parte (escolha) e a segunda parte (rejeição) da aplicação do teste eram relativamente complexas, as justificativas eram colocadas no final do protocolo do teste.

\section{Procedimento para o levantamento de dados}

Foram tabulados os dados e categorizadas as razões (ou racionalizações) para a escolha e a rejeição das respostas. Em seguida foram realizadas tabelas de freqüência: (a) cruzando a categoria com a ordem das escolhas/rejeições; (b) fazendo o levantamento das freqüências das respostas escolhidas/rejeitadas; e (c) listando as freqüências dos motivos correspondentes às escolhas/rejeições de acordo com as categorias já estabelecidas.

\section{Resultados}

\section{Ordem das escolhas e das rejeições}

No que diz respeito às escolhas, de forma coerente com o proposto por Ocampo (1976), a primeira categoria explicitada é o animal; porém, na segunda escolha, vegetal e ser inanimado se equiparam quanto à frequiência dessas categorias. A terceira escolha também apresenta consistência com as formulações de Ocampo, mas ser inanimado não fica muito à frente de vegetal, que também é bastante freqüente como última escolha.

Quanto à ordem das rejeições, a categoria mais rejeitada inicialmente foi animal e não ser inanimado, como seria de se esperar de acordo com Ocampo (1976). Na segunda re-

Tabela 1. Ordem das Categorias Escolhidas - USU - 1988

\begin{tabular}{lccc}
\hline Escolha & $\mathbf{1} \mathbf{a}$ & $\mathbf{2}$ & 3a \\
& $\boldsymbol{n}=$ & $\boldsymbol{n}=$ & $\boldsymbol{n}=$ \\
\hline Animal & 352 & 82 & 113 \\
Vegetal & 53 & 232 & 192 \\
Ser Inanimado & 93 & 175 & 249 \\
\hline Total & 498 & 489 & 554 \\
\hline
\end{tabular}

Fonte: Alunos de Psicometria do Curso de Psicologia da Universidade Santa Úrsula, sob supervisão da Prof ${ }^{\mathrm{a}}$ Guenia Bunchaft.

Tabela 2. Ordem das Categorias Rejeitadas - USU - 1988

\begin{tabular}{lccc}
\hline Rejeição & $\mathbf{1}$ & $\mathbf{2}$ & 3a \\
& $\boldsymbol{n}=$ & $\boldsymbol{n}^{\mathbf{a}}=$ & $\boldsymbol{n}=$ \\
\hline Animal & 298 & 122 & 73 \\
Vegetal & 40 & 159 & 203 \\
Ser Inanimado & 151 & 178 & 208 \\
\hline Total & 539 & 459 & 484 \\
\hline
\end{tabular}

Fonte: Alunos de Psicometria do Curso de Psicologia da Universidade Santa Úrsula, sob supervisão da Prof ${ }^{a}$ Guenia Bunchaft. jeição predominou a categoria ser inanimado, que deveria vir em primeiro lugar de acordo com essa autora; destacase, porém, a alta incidência também das categorias vegetal e animal. Na terceira rejeição, as categorias ser inanimado e vegetal ficaram empatadas, sendo rejeitada a categoria animal, ao contrário do que se poderia supor.

\section{Conteúdos escolhidos}

Procuramos nessa padronização do Teste Desiderativo estabelecer as respostas vulgares, que são as que a maioria do grupo de referência percebe. Os critérios que foram estabelecidos para saber se uma resposta é vulgar - conceito extraído do Psicodiagnóstico de Rorschach - variam de acordo com o estudioso do teste. Adotaremos aqui o critério estabelecido por Beck (1952) em relação ao Psicodiagnóstico de Rorschach, de 14 a 16\% das pessoas, ou seja, em cada seis sujeitos um faz determinada escolha (ou rejeição). Em relação ao número total dos sujeitos - 552 - temos então uma razão crítica entre 77 (14\% de 552) e 88 (16\% de 552), que seria o mínimo de freqüência para uma resposta ser considerada vulgar.

$\mathrm{Na}$ amostra estudada, foram as seguintes as respostas vulgares: árvore $(n=141$ escolhas), estrela $(n=91)$, flor $(n$ $=79)$ e ave/pássaro $(n=190)$; foram escolhidas com bastante freqüência: rosa $(n=63)$, cachorro $(n=55)$, cavalo $(n=$ $43)$, sol $(n=38)$, planta $(n=37)$, gato $(n=34)$, leão $(n=31)$, lua $(n=30)$, peixe $(n=28)$ e pedra $(n=23)$.

$\mathrm{Na}$ amostra estudada a variedade de resposta com freqüência inferior às acima (as originais) foi muito grande, não sendo exeqüível a sua transcrição integral. Podemos apenas destacar, como respostas originais interessantes: albatroz, bailarina de porcelana, beringela, banco de praça, cloreto de sódio, fóssil, jornal, dentre outras.

\section{Conteúdos Rejeitados}

Retomando os conceitos de vulgar e de original, constatamos na presente amostra três vulgares: rato $(n=83)$, capim/grama $(n=77)$ e pedra $(n=75)$, conteúdos que a maioria das pessoas rejeita face às instruções de Desiderativo. Foram ainda rejeitadas por um número significativo de pessoas: cobra $(n=68)$, planta carnívora $(n=75)$, cactus $(n=$ $44)$, cadeira $(n=44)$, vegetais venenosos $(n=28)$, flor $(n=$ $30)$, árvore $(n=49)$, cachorro $(n=24)$ e mosca $(n=24)$.

Com relação às rejeições originais encontramos a mesma dificuldade que em relação às escolhas originais, ou seja, foram numerosas e assim vamos citar apenas algumas: água, buraco negro, cipreste, copo de botequim, dinossauro, fóssil, fita-pirata, lava, político brasileiro etc.

\section{Motivos assinalados para as escolhas}

As racionalizações mais freqüentemente atribuídas às escolhas foram: (1) Liberdade $(n=214)$; (2) Impacto Estético $(n=214)$ e (3) Utilidade/Reparação $(n=175)$. Também tiveram alta incidência as seguintes racionalizações: (1) Su- 
avidade/Falta de Dano $(n=65)$; $(2)$ Despertar Admiração/ Fascinar ( $\mathrm{n}=90)$; (3) Ser Apreciado/Querido/Necessário ( = 55); (4) Poder/Domínio $(n=79)$; (5) Valorização do Corpo/Sensações $(n=55)$ e $(6)$ Movimento $(n=88)$.

\section{Motivos assinalados para as rejeições}

As rejeições, da mesma forma que as escolhas, apresentam uma ampla gama de racionalizações, dentre as quais se destacam: (1) Agressividade/Destruição/Dano ( $n=195)$; (2) Asco/Repulsa ( $\mathrm{n}=157)$; (3) Sensações Desagradáveis $(\mathrm{n}=$ 139); Sentimentos Desagradáveis $(n=109)$; (4) Submissão $(\mathrm{n}=88)$ e $(5)$ Sujeira $(\mathrm{n}=88)$.

\section{Discussão dos Resultados}

\section{Ordem das escolhas}

Em relação à ordem das escolhas, observamos alguns resultados inesperados. Segundo Ocampo e suas colaboradoras (1976, p.75), a ordenação "normal" seria dar como primeira resposta um animal, em segundo lugar um vegetal e em terceiro um ser inanimado. Tal fenômeno ocorreria devido à crescente desvitalização das categorias assim escolhidas, o que força o indivíduo a se defrontar com a morte e a perda de identidade (Mandatos "Não Vivas" e "Não Sejas"). As autoras acima citadas propõem que o oposto ocorreria com as rejeições, sendo a primeira categoria rejeitada o ser inanimado, a segunda a do vegetal e a terceira a do animal, pelas mesmas razões que determinam a ordem das escolhas.

Uma possível explicação para essas inversões se situa na amplitude da categoria ser inanimado, formulada por Ocampo e cols. (1976), que transformamos numa categoria que abrange seres inanimados, abstrações, elementos e forças da natureza etc.

Acreditamos que abstrações como "amor" e "compreensão", bem como elementos da natureza como estrela, cometa etc. podem ter sido escolhidos preferencialmente em relação a vegetais e mesmos animais, devido ao caráter positivo que geralmente se empresta a tais abstrações. Parece válido concluirmos aqui, então, que além do simples critério de despersonalização, seria necessário considerar também outros critérios em relação ao teste. Em outras palavras, o Teste Desiderativo, ao que tudo indica, é realmente mais amplo do que parece à primeira vista, fornecendo outros dados além dos relativos ao medo da despersonalização/perda de identidade. Estaríamos lidando aqui com uma série de outros aspectos da personalidade, como expectativas, anseios etc. A esse respeito, Ocampo e cols. (1976, p. 65-91) mencionaram, entre outros dados a serem detectados: força do ego, mecanismos de defesa e índices prognósticos.

A variação do número de escolhas (alguns sujeitos não escolheram determinadas categorias) deveu-se, acreditamos, a fatores diversos, dentre os quais: a resistência dos sujeitos a ingressarem em outra(s) categoria(s) além da(s) inicialmente escolhida(s) (por exemplo, "se não posso ser animal não quero ser qualquer outra coisa"); ou aversão por determinada categoria (por exemplo "Ah, jamais gostaria de ser um vegetal") ou, ainda, por um bloqueio ou desbloqueio frente ao estímulo novo representado pelo teste ("se não posso ser uma pessoa não quero ser nada" é um exemplo de bloqueio).

\section{Conteúdo em termos de Análise Transacional}

De acordo com Ocampo e cols. (1976, p. 92-93) as escolhas (o que a pessoa gostaria de ser) revelam os mecanismos de defesa (como a pessoa se defende) o que, em Análise Transacional corresponderia, de certa forma, aos Compulsores. Por exemplo, o indivíduo diz que quer ser um copo de cristal. O cristal é um objeto aparentemente forte e internamente frágil. Isso, em Análise Transacional, sugere a atuação do Compulsor Seja Forte, dado o medo de evidenciar sua fragilidade e perder o controle de suas emoções, o que o indivíduo tenta evitar por meio de uma fortaleza aparente.

Como as rejeições (o que o indivíduo não gostaria de ser) revelam do que o indivíduo se defende, tais respostas, possivelmente, evidenciam os Mandatos do indivíduo, assim como a sua Ameaça Argumental. Por exemplo, rejeitar bomba, um objeto ligado à agressividade, que simboliza pulsões violentas e desintegradoras, implicaria no Mandato "Não Sintas o que Sentes Porque és Mau".

Note-se que, neste exemplo, o indicador ("rejeição a bomba") se refere a um Mandato ("Não Sintas o que Sentes Pois é Mau") que está sendo aceito pelo indivíduo, que não quer sentir agressividade. Mas um indicador, acreditamos, também pode se referir a um Mandato contra o qual o indivíduo esteja lutando (como é o caso de um cliente em terapia).

A escolha positiva de Pássaro (190 escolhas em uma amostra de 552 sujeitos) nos parece ligada a um anseio de liberdade, que refletiria a aspiração da Criança (em Análise Transacional) a se tornar o Príncipe que, segundo Berne, é a identidade primária e positiva do ser humano. As mesmas considerações se aplicam à escolha da Estrela (91 escolhas). A esse respeito, cabe assinalar que o Pássaro poderia ser visto como mais relacional que a Estrela - elemento afastado, longínquo e isolado. Quanto a estas características, a Estrela poderia remeter à busca da perfeição, correspondendo talvez ao Compulsor Seja Perfeito, dentro de uma Posição Existencial + / - (afastar-se de) - seria distante e perfeita.

Outra escolha positiva encontrada como vulgar (141 escolhas), a Árvore, refletiria a necessidade de permanência e de continuidade face à possível perda de identidade vinculada à fantasia de morte suscitada pelo Teste Desiderativo. A Árvore, enraizada, lembra estabilidade e permanência, seus frutos dão a idéia de continuidade. Seria uma forma de reparar a perda da vida e da identidade como ser humano. Esta escolha foi considerada por Ocampo e cols. (p. 80-82) como índice de bom prognóstico, evidenciando saúde mental; no entanto, sugerimos que se investigue a possibilidade de atuação do Compulsor Seja Forte - dependendo das características da árvore do indivíduo. 
A escolha Flor (79 escolhas), finalmente, estaria ligada ao senso estético, associada também ao Compulsor Agrade Sempre.

No que diz respeito às rejeições, a mais freqüente foi o Rato (83 rejeições em 552 sujeitos), que pode ser associado às idéias de sujeira, doença e, conseqüentemente, morte - o rato é sujo e transmissor de doenças. Teríamos aí uma resposta vulgar coerente com a proposta do teste de eliciar a fantasia de morte o que, em Análise Transacional, seria expresso pelos Mandatos Não Sejas / Não vivas (perda de identidade / da vida) e pela Ameaça Argumental Morrer.

Outra das principais rejeições, Capim/Grama (77 rejeições) também nos parece ligada à fantasia de aniquilação, ao temor de se encontrar exposto às intempéries, de ficar desprotegido, vulnerável e abandonado - numa clara indicação de Ser Abandonado como Ameaça Argumental. O indivíduo rejeita ser Grama/Capim que fica passivo, exposto ao outro que pode pisá-lo e destruí-lo. Assim, o temor seria de que a relação com o outro destruísse o indivíduo, por isso ele seguiria os Mandatos Não te Aproximes (pois serás destruído por "eles").

Finalmente, Pedra (75 rejeições) poderia ser indicativa do Mandato Não Sintas - contra o qual o indivíduo estaria lutando. Aqui, o indivíduo não quer ser Pedra para poder sentir. Apesar de a Pedra ser algo permanente - mais do que a Árvore - é rejeitada, priorizando-se o sentir. Nessa medida, a rejeição Pedra seria mais positiva que a rejeição Rato e Grama - onde se estaria cumprindo o respectivo Mandato.

A emissão das respostas consideradas vulgares indicaria participação nas normas sociais e no pensamento coletivo, correspondendo, em Análise Transacional, à adequação do Estado do Eu Pai; o fato de as vulgares fornecerem também um critério de realidade remete à "okeidade" do Adulto. A escolha de pelo menos uma vulgar seria um dos indicadores da adequação do Adulto. Quando o número de respostas vulgares aumenta, isto significaria que o conformismo social é excessivo, sendo o sujeito muito influenciável; está aí havendo uma contaminação do Adulto por parte do Pai, predominando no Estado do Eu Criança a Criança Submissa. O número de vulgares diminuído poderia evidenciar o desejo de contrariar idéias recebidas (Criança Rebelde), chegando, em casos exacerbados, a ser indicador de distúrbio psicótico.

As respostas originais - aquelas que apresentam freqüência de menos de uma em 100 respostas - corresponderiam ao Estado do Eu Criança Livre, tendo também relação com a criatividade, a intuição, a flexibilidade cognitiva e emocional. O excesso de respostas originais poderá indicar, da mesma forma que a falta de vulgares, falta de adequação do Pai e possível distúrbio psicótico. As respostas originais são as mais reveladoras das características de personalidade, pois evidenciam um posicionamento pessoal do indivíduo. Por isso, deverão ser levadas em conta com cuidado, considerando-se também como o indivíduo elabora essa resposta, de forma rica ou pobre, coerente ou incoerente.

Em resumo: vulgares e originais nas rejeições são interpretadas com os mesmos critérios que essas categorias nas escolhas, correspondendo a conformismo social, Estados do Eu Pai e Criança Livre, "okeidade" do Adulto.

\section{Motivos para as escolhas e rejeições}

As autoras deste trabalho usaram, por razões óbvias, o termo "racionalização" para designar o motivo apresentado pelo sujeito para suas escolhas e rejeições.

Note-se que esta seção se refere àquilo que é admitido pelo sujeito, e ao que isso poderia significar, em termos de Análise Transacional - sem prejuízo, é claro, do que os conteúdos das escolhas e rejeições dizem a respeito da personalidade do indivíduo. Pelo contrário, seria o caso de priorizarmos, mesmo, o que é indicado pelos conteúdos, como dando uma visão mais profunda do indivíduo - da qual ele próprio não se apercebe.

Fica claro, portanto, que os dados desta seção devem ser considerados como complementares à interpretação apresentada na seção "Conteúdos em Termos de Análise Transacional", sendo as duas seções separadas apenas por motivos de ordenação da exposição.

Uma das racionalizações mais freqüentemente atribuídas às escolhas foi Liberdade: possivelmente, indicando o anseio por maior autonomia, maior expressão da própria individualidade, uma busca de sua Criança Livre (ver o que foi dito acima sobre a escolha de "pássaro").

As racionalizações Impacto Estético e Despertar Admiração/Fascinar estariam associadas, no circuito negativo, ao jogo de sedução e aos Compulsores Seja Perfeito e Agrade Sempre; no circuito positivo, à Criança Livre aumentada.

As racionalizações Poder/Domínio e Onipotência nos parecem indicativas - de forma ainda mais acentuada do que as duas anteriores - da Posição Existencial +/-, Pai Crítico aumentado e possível Compulsor Seja Perfeito e/ou Seja Forte.

Já a racionalização Utilidade/Reparação nos parece ligada à Posição Existencial -/+, e ao Compulsor Agrade Sempre, no circuito negativo; no circuito positivo, estaria associada à adequação do Pai Nutritivo.

A racionalização Movimento seria indicativa do Compulsor Seja Apressado, no circuito negativo, e ao interesse em Evolução/Aperfeiçoamento, ligado à Autonomia, no circuito positivo.

No que diz respeito aos motivos associados às rejeições, Agressividade/Destruição/Dano estariam vinculados ao Compulsor Agrade Sempre, no circuito negativo e ao controle da agressividade no circuito positivo. O Mandato, no caso, seria Não Sintas o que Sentes, referente à emoção de raiva e a sua expressão. A Ameaça Argumental poderia ser Ser Abandonado ou Ficar Louco (que se manifesta pelo típico medo de perder o controle).

As racionalizações Asco/Repulsa e Sujeira indicariam Adulto $O K$ no circuito positivo e, no negativo, o Mandato Não Sejas (ver o que foi dito anteriormente sobre a rejeição do conteúdo Rato).

As racionalizações Sensações Desagradáveis/Sentimentos Desagradáveis implicariam em um critério de avaliação 
por parte da Criança Livre OK e NOK. Consideramos que, no caso, seria preciso uma investigação mais minuciosa, a fim de se identificar o Mandato e a Ameaça Argumental correspondente a partir das sensações/sentimentos mencionados, com referência às rejeições específicas, ligadas à esfera do sentir. É evidente que uma rejeição a flores com a racionalização "por que me lembram cemitério e morte" aponta numa direção bem diferente de uma rejeição a flores porque "não quero que ninguém venha ficar me cheirando".

A racionalização inutilidade estaria associada, no circuito negativo, aos Compulsores Agrade Sempre e Seja Esforçado, ao Mandato Não Seja Capaz e à Ameaça Argumental Ser Abandonado; corresponderia, no circuito positivo, à Socialização.

A racionalização Submissão estaria associada à Criança Rebelde aumentada, no circuito negativo, e à Criança Livre ok no positivo. Pode-se pensar, a respeito dessa racionalização, que ela estaria associada aos Mandatos Não Sejas (como defesa em relação à despersonalização) ou Não Vivas.

\section{Conclusões}

Verificamos, no presente estudo, que o Teste Desiderativo teria ampla aplicação no diagnóstico clínico, tendo como referencial teórico a Análise Transacional. Ele permite a identificação de elementos básicos da personalidade: Estados do Eu, Compulsores, Ameaças Argumentais, Mandatos e Posições Existenciais. Nosso estudo indicou, sobretudo, que o referido instrumento é eficiente para se medir o nível de "okeidade" do Adulto, expresso por meio do critério de realidade do indivíduo. O Teste também fornece parâmetros para se avaliar a possível contaminação do Adulto pelo Pai e pela Criança, graças ao levantamento das vulgares. É possível, igualmente, uma avaliação da Criança Livre, por meio da análise das respostas originais.

Por outro lado, é de se notar que na amostra estudada determinados aspectos parecem muito pregnantes, como o anseio pela liberdade, a grande presença do Compulsor Agrade Sempre e a Posição Existencial +/-. Queremos destacar, a esse respeito, que a pesquisa foi feita com uma amostra composta única e exclusivamente de universitários e, em esmagadora maioria, de adolescentes e adultos jovens, o que explicaria os achados acima. Não custa lembrar que é próprio do jovem o anseio pela liberdade e o desejo de afirmação, muitas vezes numa posição +/- defensiva de -/+, o que se evidencia também pela emergência dos Compulsores Seja Perfeito e Agrade Sempre.

Um ponto interessante a notar é que foi pouco observado o Compulsor Seja Forte - possivelmente por sua gradual desvalorização em nossa cultura, em particular numa camada mais "esclarecida" psicologicamente. Nos últimos anos, na verdade, tem havido uma divulgação intensa da condenação a aspectos comportamentais associados ao Compulsor Seja Forte, tais como o "machismo".

Ao mesmo tempo, embora tendo sido reveladores das características da faixa sócio-etária-cultural em questão, os resultados do estudo não podem ser aplicados à população em geral; isso porque trabalhamos com uma amostra com características específicas.

\section{Referências}

Anderson, H.H. \& Anderson, G.L. (1951). An introduction to projective techniques. New York: Prentice Hall.

Beck, S.J. (1952). Rorschach's test. New York: Grune \& Straton.

Berne, E. (1972). What do you say after you say hello? New York: Grove Press.

Bernstein, J. (1980). Tests proyectivos lúdicos, verbales y gráficos. Em Bell, J.E. (Org.) Técnicas proyectivas (pp. 251-285). (G.A. Maci, Trad.). Buenos Aires: Paidós (Trabalho original publicado em 1948).

Bunchaft, G \& Vasconcellos, V.L.P. (1998). Os Testes Projetivos em uma Perspectiva não Psicanalítica; Psicologia Clínica, PósGraduação e Pesquisa, 10, 7-23 (Departamento de Psicologia - PUC - Rio)

Córdoba, J. \& Pigem, J.M. (1946). La expresión desiderativa como manifestación de la personalidad Medicina Clínica, 4(3), 2023.

Guardo, R.G.M.(1969). Historia General del Psicoanálisis. Buenos Aires: Ciordia.

Kertész, R. \& Induini, G. (1977). Manual de Análise Transaccional. Buenos Aires: Conantal.

Klein, M. (1980). Novas Tendências na Psicanálise. (A. Cabral, Trad.) Rio de Janeiro: Zahar (Trabalho original publicado em 1955).

Klopfer, B. \& Kelley, D. (1974). Técnica del psicodiagnóstico de Rorschach (V.L.S. de Campo, Trad.) Buenos Aires: Paidós (Trabalho original publicado em 1946).

Ocampo, M.L.S., Arzeno, M.E.G., Friedenthal, H. Schust, M.C., Piccolo, E.G., Brodesky, A., Madanes, N., Rabinovich, D., Hirsch, S.B., Efron, A.M., Frainberg, E., Kreiner, Y., Sigal, A.M., Woscoboinik, P. \& Kornblit, A. (1976). Las técnicas proyectivas y el proceso psicodiagnóstico. Buenos Aires: Nueva Visión.

Pigem, J.M. (1949). La prueba de la expresión desiderativa. Libraria de Ciências Médicas: Barcelona.

Rorschach, H. (1974). Psicodiagnóstico (M.S. de Villemor Amaral, Trad.) São Paulo: Mestre Jou. (Trabalho original publicado em 1921)

Schust, M.C. \& Picolo, E.G. (1976). Indices diagnósticos y pronósticos em el Test desiderativo a partir del estudio de las defensas. Em Ocampo, M.L.S. (Org.). Las técnicas projectivas y el processo psicodiagnóstico (pp. 83-90). Buenos Aires: Nueva Visión.

Segal, H.(1975). Introdução à obra de Melanie Klein (J. Castanõn Guimarães, Trad.). Rio de Janeiro: Imago. (Trabalho original publicado em 1964)

Steiner, C. (1976). Os papéis que vivemos na vida (G. Schlessinger, Trad.) Rio de Janeiro: Artenova. (Trabalho original publicado em 1974)

Recebido em 14.04.200

Primeira decisão editorial em 29.03.2001

Versão final em 31.05.2001

Aceito em 11.07.2001 